\title{
A VERDADE COMO UM DIREITOS HUMANO E FUNDAMENTAL NO CONTEXTO DO ESTADO DEMOCRÁTICO DE DIREITO
}

\author{
TRUTH AS A HUMAN AND FUNDAMENTAL RIGHTS IN THE CONTEXT OF THE \\ DEMOCRATIC STATE OF LAW
}

Recebido em: 25/08/2020

Aprovado em: 10/12/2020

RESUMO: O presente artigo tem como objetivo discutir o problema da verdade no contexto do Estado Democrático de Direito moderno. Trata-se de uma questão relevante à justificação e ao fundamento das escolhas e reformas das políticas, econômicas e jurídicas. Por meio de uma pesquisa doutrinária (teórica), jusfilosófica e documental, alerta-se acerca do direito à verdade que todo cidadão tem no campo decisional político, econômico e jurídico. O ensaio discute a questão das inverdades como motivo ou causa dos atuais problemas sociais e jurídico, quando há necessidade de reformas. Discute-se o efeito negativo da verdade permeada de influências ideológicas e seus efeitos na negação da dignidade e do desenvolvimento. A metodologia eleita foi o método dedutivo, por meio de pesquisa bibliográfica e documental (normativa) brasileiras e estrangeiras, tendo como marcos teóricos as obras "Os problemas da verdade no Estado Constitucional", de Peter Häberle, "Práticas da argumentação jurídica: técnicas do raciocínio e da persuasão judicial", de Pablo Jiménez Serrano, nelas se definem os critérios para uma verdade prática e a natureza complexa das verdades jurídicas. Conclui-se que existe um direito humano à verdade, razão pela qual os cidadãos têm direito à verdade num Estado Democrático de Direito onde se almeja a cidadania, a justiça e o bem comum.

Palavras-chave: Direito à verdade. Direitos humanos fundamentais. Estado Democrático de Direito. Cidadania. Justiça. Bem comum.

ABSTRACT: This article aims to discuss the problem of truth in the context of the modern
Democratic Rule of Law. It is an issue relevant to the justification and rationale for political,
economic and legal choices and reforms. Through a doctrinal (theoretical), jusphilosophical and
documentary research, it is alerted about the right to the truth that every citizen has in the political,
economic and legal decision-making field. The essay discusses the question of untruths as a reason
or cause for current social and legal problems, when reforms are needed. The negative effect of
truth permeated by ideological influences and its effects on the denial of dignity and development
are discussed. The chosen methodology was the deductive method, through bibliographic and 
documentary (normative) research, both Brazilian and foreign, having as theoretical frameworks the works "The problems of truth in the Constitutional State", by Peter Häberle, "Practices of legal argumentation: techniques of reasoning and judicial persuasion ", by Pablo Jiménez Serrano, define the criteria for a practical truth and the complex nature of legal truths. We conclude that there is a human right to the truth, which is why citizens are entitled to the truth in a Democratic State of Law where citizenship, justice and the common good are sought.

Keywords: Right to the truth. Fundamental human rights. Democratic state. Citizenship. Justice. Very common.

SUMÁRIO: Introdução; 1 Os problemas das verdades na jusfilosofia moderna; 1.1 Problemas do relativismo das verdades; 2 Para uma teoria acerca dos fundamentos da verdade; 2.1 Fundamento empírico-sociológico (concepção oriunda do Mundo 1); 2.2 Fundamento teórico-discursivo (concepção oriunda do Mundo 2); 2.3 Fundamento metafísico (concepção oriunda do Mundo 3); 3 O problema da verdade no estado democrático de direito; 3.1 Verdades práticas para uma razão comum. Conclusão. Referências.

\section{INTRODUÇÃO}

A teoria da verdade, na transição para democracias pluralistas dos países em desenvolvimento, coloca um problema na ordem do dia da nossa ciência constitucional, problema que tem recebido pouca atenção pela doutrina moderna ${ }^{1}$.

Esse problema repercute, seriamente, na consolidação do Estado Democrático de Direito fundado na competência sobre a verdade no âmbito geral e parcial, principalmente, quando há necessidade de reformas.

As questões preponderantes a serem considerada neste tema são as seguintes: 1 . No contexto de um Estado Democrático de Direito, tem o cidadão direito à verdade? 2. Existe um direito humano à verdade? 3. As democracias modernas hão de estar, necessariamente, fundamentadas no critério de verdade?

O presente artigo tem como objetivo discutir essas questões no contexto do Estado Democrático de Direito moderno. Trata-se de uma investigação relevante à justificação e ao fundamento das escolhas e reformas das políticas, econômicas e jurídicas.

Por meio de uma abordagem doutrinária (teórica), jusfilosófica e documental, discute-se o direito à verdade que todo cidadão tem na arena política, econômica e jurídica.

O ensaio apresenta a questão das inverdades como motivo ou causa dos atuais problemas sociais e jurídico, principalmente, quando há mudanças sociais, econômicas e necessidade de reformas.

No artigo alerta-se acerca do efeito negativo da verdade permeada de influências ideológicas e seus efeitos na negação da dignidade e do desenvolvimento.

A metodologia eleita foi o método dedutivo, exegético e analítico, métodos de grande utilidade na pesquisa bibliográfica e documental (normativa) brasileiras e estrangeiras, tendo como marcos teóricos as obras "Os problemas da verdade no Estado Constitucional", de Peter Häberle, "Práticas da argumentação jurídica: técnicas do raciocínio e da persuasão judicial", de Pablo Jiménez Serrano, obras onde se definem os critérios para uma verdade prática e a natureza complexa das verdades jurídicas.

\footnotetext{
${ }^{1}$ HÄBERLE, Peter. Os problemas da verdade no estado constitucional. Trad. Urbano Carvelli. Porto Alegre: Sergio Antonio Fabris Ed., 2008. p. 29.
} 
Conclui-se que existe um direito humano à verdade, razão pela qual os cidadãos têm direito à verdade num Estado Democrático de Direito onde se almeja a cidadania, a justiça e o bem comum.

\section{OS PROBLEMAS DAS VERDADES NA JUSFILOSOFIA MODERNA}

O que mais preocupa ao estudante, ao jurista e ao homem de ciência modernos é o fato de poder se posicionar perante os sucessivos conflitos doutrinários (conceituais) e decisórios (jurisprudenciais) presentes nas democracias modernas e, ainda, nas decisões políticas, tudo o que nos autoriza a exigir um direito à verdade. A mesma preocupação existe em relação ao direito à informação, razão pela qual o tema das "Fake News" tem-se tornado um problema visível no processo de divulgação mediática que acontece nos jornais impressos, digitais e televisivos.

O conceito de verdade, aspecto aqui considerado como o problema-objeto de toda reflexão jurídica e filosófica, por servir de referencial para a avaliação do significado de qualquer afirmação ou proposição.

De acordo com diversas concepções, a verdade pode ser, por exemplo, uma declaração filosófica a qual pode ser verificada por meio de critérios lógicos, linguísticos, empíricos ou outros qualquer $^{2}$.

Certamente, a reflexão filosófica continua impregnada de incertezas, pois como ensina Descartes $^{3}$ :

o poder de bem julgar e distinguir o verdadeiro do falso, é, naturalmente, igual em todos os homens, do que resulta que a diversidade de opiniões existe, não porque uns são mais sensatos que outros, mas somente por conduzirmos nossos pensamentos por diversos caminhos e não considerarmos a mesma coisa.

Contudo, as diferentes formas de significar a verdade têm dado origem às divergentes escolas jusfilosóficas que, por sua vez, influenciaram na diversificação das teorias jurídicas.

Por esse motivo, muitas são as divergências a respeito da verdade numa área do saber tão complexa como o Direito. Tais divergências são oriundas da ideia de que "algumas coisas são certas por natureza, já outras são certas meramente por convenção ou por legislação"4.

Talvez tais divergências não acontecem noutras áreas do saber humano. Os lógicos e os matemáticos, afirma ${ }^{5}$ necessitam de um só conceito de verdade, a saber, o de verdade formal.

Mas, no Direito é diferente. Nesta área do saber humano, as verdades jurídicas estão relacionadas à discussão acerca dos domínios do Direito, tema objeto das diversas reflexões na seara da Filosofia Jurídica e que tem como finalidade a compreensão das razões dos reducionismos e, consequentemente, do relativismo jurídico.

Neste sentido, vale perguntar: existem verdades jurídicas? ou melhor, que é uma verdade?

Para tentar dar resposta a essas questões importa considerar a verdade como a afirmação ou o juízo que resulta da relação que existe entre o conhecimento que deriva quer da experiencia, da lógica e da razão. E, nisso radica o problema das verdades, pois, até não serem socialmente convencionadas, nem todos temos as mesmas razões para acreditar e agir.

Assim sendo, as verdades jurídicas, diferentemente de outras ciências, são relativas, pois as divergências tornam-se mais evidente no Direito. Pensando na relação existente entre "verdades" e "ciência", podem-se qualificar as verdades das ciências exatas como permanentes, as verdades

\footnotetext{
${ }^{2}$ HÄBERLE, Peter. Os problemas da verdade no estado constitucional. Trad. Urbano Carvelli. Porto Alegre: Sergio Antonio Fabris Ed., 2008. p. 31.

${ }^{3}$ DESCARTES, René. Discurso do método. Trad. Lourdes Nascimento Franco. São Paulo: Ícone, 2006, p. 15, 29.

${ }^{4}$ MacCORMICK, Neil. Argumentação jurídica e teoria do direito. Trad. Waldéa Barcellos revisão da tradução Marylene Pinto Michael. São Paulo: Martins fontes, 2006, p. 1.

${ }^{5}$ BUNGE, Mario. Tratado de Filosofia Básica. Semântica II: Sentido e Referência. Trad. de Leônidas Hegenberg e Octanny S. da Mota. São Paulo: E.P.U Ed. da Universidade de São Paulo, 1976b, p. 93.
}

Revista de Direito Brasileira | Florianópolis, SC | v. 27 | n. 10 | p.14-30 | Set./Dez. 2020 
das ciências naturais como transitórias e as verdades das ciências humanas, onde incluímos o Direito, como relativas.

Agora, é importante distinguir a verdade da crença, pois ambos os conceitos não se confundem. Assim, por exemplo, explica Bunge ${ }^{6}$ : pode-se crer em falsidades e descrer de verdades e todos ignoramos a maior parte das verdades e a maior parte das falsidades. Neste sentido, verdade e crença são coisas distintas, embora não obrigatoriamente separadas. O conceito semântico de verdade e o conceito pragmático (ou psicológico) de crença (pessoal ou coletiva) fundem-se no de verdade pragmática, ou verdade para alguém. Mas exatamente, há dois desses conceitos: verdade pessoal (subjetiva) e verdade coletiva (ou intersubjetiva) que não devem ser confundidas com a verdade objetiva.

Como será explicado nas próximas seções, diferentemente de outras áreas do saber humano, no Direito trabalha-se com três tipos de verdades.

O primeiro tipo de verdade, V1, a (verdade de correspondência) é aquela fundamentada empiricamente e, portanto, deriva da correspondência entre os que pesamos e afirmamos e os fatos, coisas e acontecimentos constatados. Assim, V1 é um tipo de verdade que se funda numa afirmação (juízo de fato). Quando afirmamos, por exemplo: eis aqui uma coisa! (objeto: dado ou realidade) designamos um objeto ou realidade por meio de uma sentença que envolve uma verdade de constatação, isto é, juízos de fatos construídos a partir de uma constatação empírica.

Todavia, quando afirmamos "esta coisa (objeto) é uma caneta", "esta caneta é branca" ou "esta conduta é ilícita" estaremos, por meio dessas sentenças descrevendo uma realidade, a partir de uma correspondência (verdade de correspondência) existente entre um objeto (coisa ou conduta) e um nome (conceito: caneta) e uma qualidade (branca). Tais nomes conceitos e qualidades são previamente conhecidos e convencionados. Logo, em teoria, contamos com um referencial teórico/conceitual e, portanto, sabemos o que é uma caneta, sabemos distinguir as cores, sabemos o que é uma lei e podemos identificar seu conteúdo. No primeiro caso-exemplo, a justificação se apoia numa experiência (sensível), já no segundo num conhecimento ou convenção.

O segundo tipo de verdade, V2, (de razão discursiva ou argumentativa) se funda no conceito de coerência, trata-se de uma verdade maiormente demonstrável por meio de processos (operações) lógicos que recaem sobre crenças, leis e princípios. Assim, por exemplo, quando afirmamos "Caim matou Abel" estaremos afirmando uma verdade que depende de uma crença que exige a aceitação de que o fato histórico realmente existiu e, para considerá-lo verdadeiro, somos coerentes com a nossa fé, pela impossibilidade real de constatação. Diferentemente de V1, este tipo de verdade não depende de uma constatação empírica, mas de processos dedutivos que desenvolvemos partindo de leis ou princípios previamente conhecidos. Assim, para poder afirmar que uma conduta é lícita ou ilícita devemos partir da análise do conteúdo da lei, para saber se a conduta está ou não tipificada como lícita ou ilícita.

Além disso, também deve ser considerado que a verdade de coerência pode estar fundada numa lei natural (física) como a gravidade, por exemplo. Por isso, as nossas afirmações se justificam pela lei que invocamos e que já foram convencionadas. Assim, por exemplo, "todo corpo abandonado a si próprio, cai" ou "a dignidade da pessoa humana é um superprincípio". Nesses casos, não seria bom tentar pular de um prédio de 5 andares sem paraquedas, como também não é correto ferir a dignidade de uma pessoa. Somos, pois, coerentes com uma lei ou princípio, portanto, as nossas afirmações e decisões estão "validadas" (legitimadas) por leis e princípios que vigora no tempo e no espaço.

$\mathrm{O}$ terceiro tipo de verdade, $\mathrm{V} 3$ é aquela fundada na razoabilidade definida por recursos oriundos do Domínio Ideológico. Trata-se de uma verdade justificada por processos axiológicos que nos ajudam a concluir que uma conduta é justa, boa ou correta. Assim, por exemplo, quando afirmamos "a corrupção é uma conduta imoral e, portanto, indesejada e reprovada socialmente",

${ }^{6}$ BUNGE, Mario. Tratado de Filosofia Básica. Semântica II: Sentido e Referência. Trad. de Leônidas Hegenberg e Octanny S. da Mota. São Paulo: E.P.U Ed. da Universidade de São Paulo, 1976b, p. 146.

Revista de Direito Brasileira | Florianópolis, SC | v. 27 | n. 10 | p.14-30 | Set./Dez. 2020 
"esta decisão é justa", "toda conduta preconceituosa é indigna”, "esta é uma boa política" etc. estamos enunciando verdades que dependem de um recurso axiológico, razão pela qual são aceitas por motivo da razoabilidade, isto é, dependem de sua possibilidade razoável fundada na razão humana e, talvez, por esse motivo, afirma-se o grande fracasso da verdade discursiva (argumentativa).

Em consonância com isso, as alegações de verdades, fundadas na aceitabilidade racional do juízo, têm conotação axiológica e não ontológica. Cabe à argumentação jurídica, aos raciocínios e ao discurso persuasivo selecionarem o tipo de verdade que, conforme a sua oportunidade e critérios de correção, será usada no processo argumentativo.

\subsection{Problemas do relativismo das verdades}

Hodiernamente há um aparente consenso de que as verdades, na maioria das ciências e, especificamente nas ciências sociais e humanas, são relativas. Uma das causas desta relatividade está na própria composição multicultural das sociedades modernas.

Desta forma, o princípio da democracia que se sabe pluralista aponta para uma forma de Estado e de sociedade onde as verdades tornam-se relativas. Nesse sentido, "a única verdade absoluta é que a compreensão da verdade deve ser relativa e toda época tem as suas verdades"7.

Os problemas que derivam do relativismo têm como cerne um critério de justificação ou de correção da conduta. O fato de uma afirmação, decisão ou ação serem consideradas certas (corretas) depende do significado e do sentido atribuídos ao conceito de certeza (correção) e esse sentido se sujeita a um conceito referente: o conceito de verdade.

Neste quesito, a lógica jurídica moderna que continua a ser definida como a teoria da dedução e não como a teoria da verdade, não ajuda em nada. Mas, ainda assim, consideramos que é perfeitamente possível sujeitar o processo lógico a um conjunto de enunciados que não sejam inteiramente verdadeiros nem totalmente falsos. Necessitamos, portanto, de uma teoria da verdade parcial de fato, coerente com a lógica jurídica ${ }^{8}$.

Surge, assim, a necessidade de averiguar, primeiro, o que é verdade, para logo discutir se o que é verdadeiro é sempre correto e se podemos ou devemos atribuir a esses conceitos o mesmo significado. Deste modo, para o senso comum inexiste identidade entre esses conceitos. De maneira que o que, por momento consideramos verdadeiro nem sempre é correto.

O problema se agrava pela diversidade de sentidos atribuídos à verdade, sendo certo que, no plano das opiniões, todos têm razão e, por isso, ninguém a tem. Daí a importância dos convencionalismos e do diálogo, principais instrumentos da convivência social. Contudo, afirmase superada a teoria da verdade aristotélica, pois não mais se considera verdade como a correspondência da asserção à realidade, mas algo construído discursivamente, o que significa ser científico o resultado do consenso alcançado em relação ao objeto estudado. Isso faz com que as técnicas de argumentação sejam de extrema importância para o trabalho jurídico. Mas, como fazer para construir argumentos relevantes ou fortes?'.

Como veremos, a seguir, o maior problema do conceito de verdade é seu critério de verificação (justificação ou correção). A respeito desses critérios, subsistem variadas teorias e formas dele ser significado, a saber, a teoria da correspondência e a teoria da possibilidade razoável de afirmação. No plano da argumentação, como veremos, ambas as teorias são de extrema

\footnotetext{
${ }^{7}$ HÄBERLE, Peter. Os problemas da verdade no estado constitucional. Trad. Urbano Carvelli. Porto Alegre: Sergio Antonio Fabris Ed., 2008. p. 35, 39.

${ }^{8}$ BUNGE, Mario. Tratado de Filosofia Básica. Semântica II: Sentido e Referência. Trad. de Leônidas Hegenberg e Octanny S. da Mota. São Paulo: E.P.U Ed. da Universidade de São Paulo, 1976 b.

${ }^{9}$ ALEXY, Robert. Teoria da argumentação jurídica: a teoria do discurso racional como teoria da fundamentação jurídica. Trad. Zilda Hutchinson Schild Silva; rev. e introdução à edição brasileira Claudia Toledo. 2 ed. São Paulo: Landy, 2005.
} 
importância para o jurista empenhado em saber o que é fazer a coisa certa e essa noção repercute tanto na certeza do conhecimento como das nossas decisões.

Para Habermas ${ }^{10}$, por exemplo, o conceito de conhecimento como representação é indissociável do conceito de verdade como correspondência. Assim, afirma o citado autor, não podemos renunciar ao primeiro sem perder também o segundo. Se a linguagem e a realidade se interpenetram de uma maneira indissolúvel, a verdade de uma sentença só pode ser justificada com a ajuda de outras sentenças já tidas como verdadeiras e, portanto, como fundamento.

Mario Bunge ${ }^{11}$ também considera que existe uma verdade de fato e uma verdade de razão. Quanto a esta última afirma que é aquela que pode ser estabelecida por força apenas da razão, destacando, assim, numerosas espécies: a) Verdades por definição nominal (ou convencionadas); b) Verdades por imposição ou postulado; c) Verdades por demonstração ou dedução; d) Verdades lógicas e; e) Verdades por exemplificação. Todas, obviamente, com fundamentos diferentes.

\section{PARA UMA TEORIA ACERCA DOS FUNDAMENTOS DA VERDADE}

Mas, como saber se uma afirmação é verdadeira? Quais são as razões que justificam a verdade? Há conhecimento sem justificação?

As respostas reservadas para essas perguntas podem ser diversas, pois, envolvem três importantes razões ou fundamentos de justificação que, a seguir, serão estudadas, a saber: a) empírico-sociológica (concepção oriunda do Mundo 1); b) teórico-discursiva (concepção oriunda do Mundo 2) e; c) metafísico (concepção oriunda do Mundo 3).

Para melhor compreender o assunto, definimos o conhecimento como ideias ou um conjunto de ideias que temos acerca de uma realidade. O conhecimento é um produto ideal: uma "Crença" verdadeira ou justificada: expressa em proposições ${ }^{12}$. Logo, importa saber como justificar as nossas crenças (verdades). Estudaremos, a seguir, dois importantes fundamentos ou razões de justificação.

\subsection{Fundamento empírico-sociológico (concepção oriunda do Mundo 1)}

O primeiro fundamento de justificação parte da seguinte premissa: toda verdade da realidade objetiva: fenômenos ou acontecimentos. Diz-se, assim, de um fundamento ontológico por meio do qual se afirma que "nada há em nossa inteligência que não haja entrado nela por meio dos sentidos"13.

Pois bem, o fundamento empírico-sociológico da verdade se funda na relação de conformidade do nosso pensamento com uma realidade (exatidão): trata-se da correspondência, que anteriormente chamamos de V1.

Neste sentido, afirma Bunge ${ }^{14}$ : uma vez que a teoria da verdade em termos de "coerência" não se preocupa com a referência factual, poderia parecer que nos devêssemos voltar para a concepção de verdade em termos de "correspondência", sendo essa, aquela que afirma que um enunciado é verdadeiro caso se ajuste aos fatos.

\footnotetext{
${ }^{10}$ HABERMAS, Jürgen. A ética da discussão e a questão da verdade. Organização e introdução de Patrick Savidan; trad. Marcelo Brandão Cipolla. São Paulo: Martins Fontes, 2004, p. 42, 59.

${ }^{11}$ BUNGE, Mario. Tratado de Filosofia Básica. Semântica II: Sentido e Referência. Trad. de Leônidas Hegenberg e Octanny S. da Mota. São Paulo: E.P.U Ed. da Universidade de São Paulo, 1976b, p. 103.

${ }^{12}$ GRAYLING, A. C. Epistemolgia, in BUNNIN, Nicholas e E.P. Tsui-James (orgs). "Compendio de Filosofia". São Paulo: Loyola, 2002, p. 40, 41.

${ }^{13}$ POPPER, Karl. R. Conhecimento objetivo: uma abordagem evolucionária. Trad. de Milton Amado. Belo Horizonte: Itatiaia, 1999, p. 15.

${ }^{14}$ BUNGE, Mario. Tratado de Filosofia Básica. Semântica II: Sentido e Referência. Trad. de Leônidas Hegenberg e Octanny S. da Mota. São Paulo: E.P.U Ed. da Universidade de São Paulo, 1976 b, p. 107.
}

Revista de Direito Brasileira | Florianópolis, SC | v. 27 | n. 10 | p.14-30 | Set./Dez. 2020 
Deve-se ver, aqui que no processo de fundamentação empírica onde lidamos com asserções referentes a matéria de fato ou a proposições existenciais em geral, quando procuramos comprovar a veracidade ou falsidade de tais asserções, a lógica tem um papel secundário, já que somente pode operar com provas já fornecidas por nossas várias impressões sensoriais ${ }^{15}$.

A respeito desse tipo de fundamento, considera-se toda verdade depende das experiências, isto é, da observação direta da coisa em si. Aceitaremos, pois, que "a verdade é uma propriedade que as proposições não podem perder - uma vez que uma proposição é verdadeira, ela é verdadeira para sempre e para qualquer público"16.

\subsection{Fundamento teórico-discursivo (concepção oriunda do Mundo 2)}

A segunda razão ou fundamento parte da seguinte premissa: podemos ter algum conhecimento ou ideia acerca de uma realidade sem que necessariamente exista constatação, isto é, sem apoio em evidência sólida (experiências). Assim, por exemplo, acreditamos e afirmamos que "o sol nascerá amanhã porque ele assim tem feito no passado".

A razão discursiva (ou argumentativa) se funda nos seguintes conceitos: a) coerência, maiormente demonstrável por meio de processos (operações) lógicos que recaem sobre crenças, leis e princípios e, por esse motivo aos efeitos desta obra chamamos de $\mathrm{V} 2 \mathrm{e}$; b) razoabilidade, definida por recursos axiológicos e que anteriormente simbolizamos com V3.

Como anteriormente vimos, no exemplo, "Caim matou Abel" está se afirmando uma verdade que depende de uma crença que exige a aceitação de que o fato histórico realmente existiu e para considerá-lo verdadeiro, somos coerentes com a nossa fé, pela impossibilidade real de constatação.

A verdade de coerência (V2), neste sentido, é aceita sempre que se acredite na existência de um objeto (fato ou conduta) com o qual não tivemos alguma experiência. Todavia, a verdade de coerência pode estar fundada, como visto, numa lei ou num princípio por meio dos quais se legitima uma "validade".

Resumidamente, podemos fixar o seguinte: trabalhamos com asserções cuja justificação se assenta num princípio ou lei de "validade" da nossa afirmação que se limita a determinado tempo e lugar.

\subsection{Fundamento metafísico (concepção oriunda do Mundo 3)}

A terceira razão ou fundamento parte da seguinte premissa: Existe uma verdade universal, permanente e anterior ao intelecto humano. Este tipo de fundamento associa a verdade a uma realidade imaginária cujos recursos somente podem ser atingidos axiologicamente. Os recursos e princípios primeiros situam-se num imaginário mundo para além do mundo empírico e sua simbologia, ondo a coerência cede lugar à razoabilidade. É, com base nesta realidade que podemos afirmar, por exemplo, a justiça social.

Este tipo de verdade (V3 ou Verdade de razoabilidade) é justificada por processos axiológicos que nos ajudam a concluir que uma determinada ação ou conduta é justa, boa ou correta. Quando afirmamos "esta decisão é injusta", estamos enunciando verdades que dependem de um recurso axiológico, razão pela qual são aceitas por motivo da razoabilidade, isto é, dependem de sua possibilidade razoável fundada na razão humana e, talvez, esta seja a grande fraqueza deste tipo de verdade.

\footnotetext{
15 MacCORMICK, Neil. Argumentação jurídica e teoria do direito. Trad. Waldéa Barcellos revisão da tradução Marylene Pinto Michael. São Paulo: Martins fontes, 2006, p. 3.

${ }^{16}$ HABERMAS, Jürgen. A ética da discussão e a questão da verdade. Organização e introdução de Patrick Savidan; trad. Marcelo Brandão Cipolla. São Paulo: Martins Fontes, 2004, p. 60.
}

Revista de Direito Brasileira | Florianópolis, SC | v. 27 | n. 10 | p.14-30 | Set./Dez. 2020 
Mas, certamente, se por um lado, os enunciados jurídicos e morais (prescritivos) que nos dizem o que fazer não devem ser equiparados às afirmações descritivas que nos dizem em como as coisas se articulam entre si; por outro lado, as prescrições se voltam para a conduta e ralações sociais e, nesse sentido, conclui Habermas ${ }^{17}$ :

A partir de um conceito discursivo da verdade, é fácil interpretar a justiça das normas e juízos morais como um análogo da verdade, sem por isso incorrer em implicações realistas. À luz de uma noção epistêmica da verdade, "encaixar-se nos fatos" não é o mesmo que corresponder aos fatos. Entretanto, depois de reformular o conceito discursivo da verdade, tenho de enfrentar mais uma vez a questão da verdade moral.

Em síntese: as três espécies de verdades jurídicas anteriormente explicadas, na prática, se complementam.

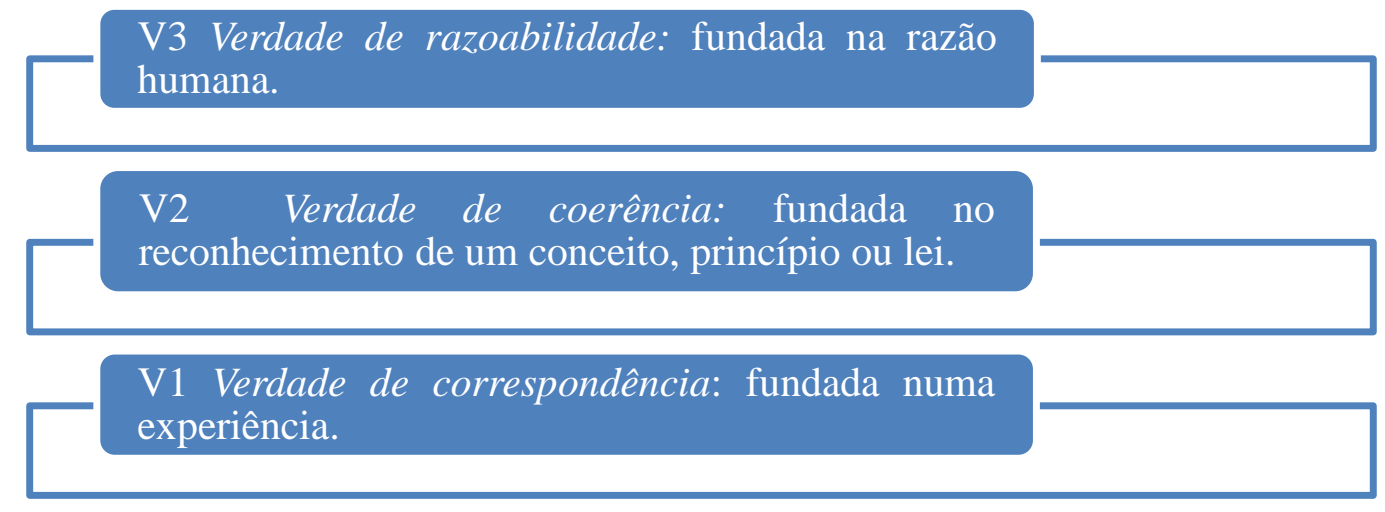

Em consonância com isso, as alegações de verdades, fundadas na aceitabilidade racional do juízo, têm conotação axiológica e não ontológica.

Assim, V1 se expressa por meio de uma proposição fundada num juízo de fato, V2 se funda numa relação lógica, V3 se funda num juízo de valor.

Independentemente das razões em destaque, todas as afirmações fundadas em verdades comunicam alguma coisa e merecem a nossa atenção, pois estão inseridas no mundo do ser e do dever ser. Neste sentido, as verdades subjetivas cedem lugar à verdades coletivas, pois, "ninguém tem a posse daquela verdade única que determina o todo" $" 18$.

Logo, cabe à argumentação jurídica e a ética do discurso discutir a utilidade e oportunidade dos critérios de correção derivados da vida coletiva, isto é, convivência social.

\section{O PROBLEMA DA VERDADE NO ESTADO DEMOCRÁTICO DE DIREITO}

Nesta seção interessa discutir as verdades sob a ótica dos textos jurídicos produzidos no contexto da realidade socioeconômica e política de um Estado Democrático de Direito, onde, assim como acontece nos países ibero-americanos, maiormente, vigora o direito escrito.

\footnotetext{
${ }^{17}$ HABERMAS, Jürgen. A ética da discussão e a questão da verdade. Organização e introdução de Patrick Savidan; trad. Marcelo Brandão Cipolla. São Paulo: Martins Fontes, 2004, p. 64.

${ }^{18}$ HÄBERLE, Peter. Os problemas da verdade no estado constitucional. Trad. Urbano Carvelli. Porto Alegre: Sergio Antonio Fabris Ed., 2008. p. 35.
} 
Nos sistemas jurídicos ibero-americanos, onde maiormente as decisões são justificadas ou fundadas nas normas de direito escrito, por ser concebido o direito como um texto ${ }^{19}$, continua a prevalecer a ideia de que ele (o direito) é um mero sistema de comunicação.

A partir dessa perspectiva, qualquer análise do fenômeno jurídico há de ser feita percorrendo o estudo do emitente, da mensagem, do meio e do receptor.

Conforme os ensinamentos de Gregorio Robles ${ }^{20}$, por exemplo, cada ordenamento jurídico é um texto gerado por atos de fala, que denominamos decisões jurídicas. As decisões geram texto num processo inacabado até que o ordenamento, por qualquer razão, desapareça. Assim, as decisões produzem texto verbalizado cujas unidades elementares chamamos de normas jurídicas. Estas normas jurídicas não são proporcionadas diretamente pelas decisões, mas, em verdade, constituem o resultado de uma reconstrução hermenêutica que opera sobre o material bruto do ordenamento. $\mathrm{O}$ conjunto das normas forma o sistema jurídico, conceito paralelo ao de ordenamento, mas que não se confunde com ele porque o sistema também é produto da reconstrução hermenêutica do material bruto que o ordenamento é.

A anterior concepção considera que o Direito se manifesta necessariamente na forma de linguagem: é linguagem, é texto. Contudo, todo direito é uma mensagem expressa em forma de texto e espera-se, assim, superar a já criticada "teoria normativa ou pura do direito".

Pois bem, é na forma de linguagem que as verdades se manifestam. Neste sentido, verdades, normas e decisões se articulam em torno de unidades mais amplas que estas últimas, chamadas instituições jurídicas. Estas refletem o aspecto organizador do texto jurídico, que não pode ser entendido como mera agregação de normas ${ }^{21}$.

O protótipo Estado Democrático de Direito repousa especificamente sobre textos positivos escritos ou verbalizados, os quais demanda um entendimento ou compreensão, e aqui a hermenêutica desempenha um importante papel, pois, de fato, "a hermenêutica também tem relevância teórico-cientifica desde que desvende, através da reflexão hermenêutica, condições da verdade dentro das ciências" 22 .

A ideia de verdade como direito em diversos textos constitucionais. Talvez, afirma Häberle, o texto mais antigo conhecido na história constitucional seja o grande enunciado da Declaração de Independência norte-americana de 1779:

Consideramos estas verdades como evidentes por si mesmas, que todos os homens são criados iguais, dotados pelo Criador de certos direitos inalienáveis, que entre estes estão a vida, a liberdade e a procura da felicidade. Que a fim de assegurar esses direitos, governos são instituídos entre os homens, derivando seus justos poderes do consentimento dos governados; que, sempre que qualquer forma de governo se torne destrutiva de tais fins, cabe ao povo o direito de alterá-la ou aboli-la e instituir novo governo, baseando-o em tais princípios e organizando-lhe os poderes pela forma que lhe pareça mais conveniente para realizar lhe a segurança e a felicidade ${ }^{23}$ (Grifo nosso).

\footnotetext{
${ }^{19}$ ROBLES, Gregorio. O direito como texto: quatro estudos de teoria comunicacional do direito. Trad. de Roberto Barbosa Alves. Barueri, SP: Manole, 2005.

${ }^{20}$ ROBLES, Gregorio. O direito como texto: quatro estudos de teoria comunicacional do direito. Trad. de Roberto Barbosa Alves. Barueri, SP: Manole, 2005.

${ }^{21}$ Tem especial importância a diferenciação entre o conceito e ordenamento e o conceito de sistema. Para o autor, o ordenamento é o texto jurídico bruto, resultado da atividade de decisão, o sistema representa o texto jurídico elaborado graças ao trabalho da dogmática jurídica. Esta não é entendida como uma ciência descritiva, mas construtiva e prática; e o sistema que ela produz é o verdadeiro centro de interesse da teoria do direito.

${ }^{22}$ HÄBERLE, Peter. Os problemas da verdade no estado constitucional. Trad. Urbano Carvelli. Porto Alegre: Sergio Antonio Fabris Ed., 2008. p. 37.

2323 
Um dos principais mecanismos pensados para garantir a concretização dessas verdades evidentes propositalmente foi consagrado no artigo 26 da Declaração Universal do Direito Humanos:

Artigo $26^{\circ}$

$[\ldots]$

2.A educação deve visar à plena expansão da personalidade humana $\mathrm{e}$ ao reforço dos direitos do Homem e das liberdades fundamentais e deve favorecer a compreensão, a tolerância e a amizade entre todas as nações e todos os grupos raciais ou religiosos, bem como o desenvolvimento das actividades das Nações Unidas para a manutenção da paz $^{24}$.

No mesmo sentido, no Preâmbulo da Constituição da República Federativa do Brasil, declarou-se o empenho da Assembléia Nacional Constituinte para instituir um Estado Democrático, destinado a assegurar o exercício dos direitos sociais e individuais, a liberdade, a segurança, o bem-estar, o desenvolvimento, a igualdade e a justiça como valores supremos de uma sociedade fraterna, pluralista e sem preconceitos, fundada na harmonia social e comprometida, na ordem interna e internacional, com a solução pacífica das controvérsias. Também, conforme o art. $1^{\circ}$ do Carta Magna brasileira se reconhece que o Estado Democrático de Direito e tem como fundamentos, dentre outros importantes princípios: a cidadania, a dignidade da pessoa humana e o pluralismo político. Por obvio, tais fundamentos são possíveis pela educação que, reconhecia como um direito social (artigo $6^{\circ}$ ) e um dever de do Estado e da família, será promovida e incentivada com a colaboração da sociedade, visando ao pleno desenvolvimento da pessoa, seu preparo para o exercício da cidadania e sua qualificação para o trabalho, artigo $205^{25}$.

Na própria Constituição Federal, no seu artigo art. 37 se estabelece que: "A administração pública direta e indireta de qualquer dos Poderes da União, dos Estados, do Distrito Federal e dos Municípios obedecerá aos princípios de legalidade, impessoalidade, moralidade, publicidade e eficiência [...]. Observa-se que o princípio da moralidade administrativa não está unicamente atrelado à cumprimento da legalidade, com base nesse princípio o agente público há de agir fundado na verdade, respeitando os valores que inspiram a justiça social.

O mesmo acontece no artigo $3^{\circ}$ da Lei $\mathrm{n}_{-}^{\mathrm{o}} 8.666$, de 21 de junho de 1993 (Regulamenta o art. 37, inciso XXI, da Constituição Federal, institui normas para licitações e contratos da Administração Pública e dá outras providências).

Art. 3ำ A licitação destina-se a garantir a observância do princípio constitucional da isonomia, a seleção da proposta mais vantajosa para a administração e a promoção do desenvolvimento nacional sustentável e será processada e julgada em estrita conformidade com os princípios básicos da legalidade, da impessoalidade, da moralidade, da igualdade, da publicidade, da probidade administrativa, da vinculação ao instrumento convocatório, do julgamento objetivo $[\ldots]$.

Todavia, a ideia da verdade como direito aparece em leis e códigos. Um dos textos básico sobre a verdade e de grande utilidade ao tema abordado é o artigo $1^{\circ}$ do Código de Ética dos

20DE\%20INDEPENDENCIA\%20DOS\%20EUA\%2004\%20de\%20julho\%20de\%201776\%20-\%20PORTUGU\%C3\%8AS.pdf. Acesso: 18 de agosto de 2020.

24 Declaração Universal do Direitos Humanos. Disponível em: https://nacoesunidas.org/wpcontent/uploads/2018/10/DUDH.pdf Acesso: 19 de agosto de 2020.

${ }^{25}$ BRASIL. Constituição (1988). Constituição da República Federativa do Brasil de 1988. Disponível em: http://www.planalto.gov.br/ccivil_03/Constituicao/Constituiçao.htm. Acesso em: 29 abr. 2020.

Revista de Direito Brasileira | Florianópolis, SC | v. 27 | n. 10 | p.14-30 | Set./Dez. 2020 
Jornalísticas Brasileiros por meio do qual se prescreve que "O Código de Ética dos Jornalistas Brasileiros tem como base o direito fundamental do cidadão à informação, que abrange direito de informar, de ser informado e de ter acesso à informação".

No próprio Código caracteriza-se, no Art. $2^{\circ}, \underline{0 \text { acesso à informação de relevante interesse }}$ público. Assim, por ser_um direito fundamental, os jornalistas não podem admitir que ele seja impedido por nenhum tipo de interesse, razão porque:

I - a divulgação da informação precisa e correta é dever dos meios de comunicação e deve ser cumprida independentemente da linha política de seus proprietários e/ou diretores ou da natureza econômica de suas empresas;

II - a produção e a divulgação da informação devem se pautar pela veracidade dos $\underline{\text { fatos }}$ e ter por finalidade o interesse público;

III - a liberdade de imprensa, direito e pressuposto do exercício do jornalismo, implica compromisso com a responsabilidade social inerente à profissão;

Já, no art. $4^{\circ}$ prescreve-se que: "O compromisso fundamental do jornalista é com a verdade no relato dos fatos, deve pautar seu trabalho na precisa apuração dos acontecimentos $e$ na sua correta divulgação".

Encontramos, igualmente, a ideia da verdade no 36 e 37 do $\mathrm{CDC}^{26}$ :

Art. 36. A publicidade deve ser veiculada de tal forma que o consumidor, fácil e imediatamente, a identifique como tal.

Parágrafo único. O fornecedor, na publicidade de seus produtos ou serviços, manterá, em seu poder, para informação dos legítimos interessados, os dados fáticos, técnicos e científicos que dão sustentação à mensagem.

Art. 37. É proibida toda publicidade enganosa ou abusiva.

$\S 1^{\circ}$ É enganosa qualquer modalidade de informação ou comunicação de caráter publicitário, inteira ou parcialmente falsa, ou, por qualquer outro modo, mesmo por omissão, capaz de induzir em erro o consumidor a respeito da natureza, características, qualidade, quantidade, propriedades, origem, preço e quaisquer outros dados sobre produtos e serviços.

[...]

$\S 3^{\circ}$ Para os efeitos deste código, a publicidade é enganosa por omissão quando deixar de informar sobre dado essencial do produto ou serviço.

Devido à importância desta regra regulam-se as consequências e prescreve-se como sanções as seguintes:

Art. 67. Fazer ou promover publicidade que sabe ou deveria saber ser enganosa ou abusiva:

Pena - Detenção de três meses a um ano e multa.

Art. 68. Fazer ou promover publicidade que sabe ou deveria saber ser capaz de induzir o consumidor a se comportar de forma prejudicial ou perigosa a sua saúde ou segurança:

Pena - Detenção de seis meses a dois anos e multa:

Art. 69. Deixar de organizar dados fáticos, técnicos e científicos que dão base à publicidade:

Pena Detenção de um a seis meses ou multa.

26 BRASIL. Lei n. 8.078, de 11 de setembro de 1990. Disponível em: http://www.planalto.gov.br/ccivil_03/leis/18078compilado.htm. Acesso em: 29 abr. 2020. 
No Código Brasileiro de Autorregulamentação Publicitária, editado em 5 de maio de 1980 se dispõe:

Artigo $1^{\circ}$ Todo anúncio deve ser respeitador e conformar-se às leis do país; deve, ainda, ser honesto e verdadeiro.

\section{$[\ldots]$}

Artigo $6^{\circ}$ Toda publicidade deve estar em consonância com os objetivos do desenvolvimento econômico, da educação e da cultura nacionais.

No Código de Ética e Disciplina da Ordem dos Advogados do Brasil - OAB se dispõe:

O CONSELHO FEDERAL DA ORDEM DOS ADVOGADOS DO BRASIL, ao instituir o Código de Ética e Disciplina, norteou-se por princípios que formam a consciência profissional do advogado e representam imperativos de sua conduta, os quais se traduzem nos seguintes mandamentos: lutar sem receio pelo primado da Justiça; pugnar pelo cumprimento da Constituição e pelo respeito à Lei, fazendo com que o ordenamento jurídico seja interpretado com retidão, em perfeita sintonia com os fins sociais a que se dirige e as exigências do bem comum; ser fiel à verdade para poder servir à Justiça como um de seus elementos essenciais; proceder com lealdade e boa-fé em suas relações profissionais e em todos os atos do seu ofício; empenhar-se na defesa das causas confiadas ao seu patrocínio, dando ao constituinte o amparo do Direito, e proporcionando-lhe a realização prática de seus legítimos interesses; comportar-se, nesse mister, com independência e altivez, defendendo com o mesmo denodo humildes e poderosos; exercer a advocacia com o indispensável senso profissional, mas também com desprendimento, jamais permitindo que o anseio de ganho material sobreleve a finalidade social do seu trabalho; aprimorar-se no culto dos princípios éticos e no domínio da ciência jurídica, de modo a tornar-se merecedor da confiança do cliente e da sociedade como um todo, pelos atributos intelectuais e pela probidade pessoal; agir, em suma, com a dignidade e a correção dos profissionais que honram e engrandecem a sua classe. Inspirado nesses postulados, o Conselho Federal da Ordem dos Advogados do Brasil, no uso das atribuições que lhe são conferidas pelos arts. 33 e 54, V, da Lei n. 8.906, de 04 de julho de 1994, aprova e edita este Código, exortando os advogados brasileiros à sua fiel observância.

\section{TÍTULO I DA ÉTICA DO ADVOGADO}

\section{CAPÍTULO I DOS PRINCÍPIOS FUNDAMENTAIS}

Art. $1^{\circ} \mathrm{O}$ exercício da advocacia exige conduta compatível com os preceitos deste Código, do Estatuto, do Regulamento Geral, dos Provimentos e com os princípios da moral individual, social e profissional.

Art. $2^{\circ} \mathrm{O}$ advogado, indispensável à administração da Justiça, é defensor do Estado Democrático de Direito, dos direitos humanos e garantias fundamentais, da cidadania, da moralidade, da Justiça e da paz social, cumprindo-lhe exercer o seu ministério em consonância com a sua elevada função pública e com os valores que lhe são inerentes.

Parágrafo único. São deveres do advogado:

I - preservar, em sua conduta, a honra, a nobreza e a dignidade da profissão, zelando pelo caráter de essencialidade e indispensabilidade da advocacia; 
II - atuar com destemor, independência, honestidade, decoro, veracidade, lealdade, dignidade e boa-fé;

[...]

Art. $3^{\circ} \mathrm{O}$ advogado deve ter consciência de que o Direito é um meio de mitigar as desigualdades para o encontro de soluções justas e que a lei é um instrumento para garantir a igualdade de todos.

As cláusulas de verdade também se expressam por meio das formalidades de juramento, tanto nos processos e audiências judiciais como de formaturas dos diversos cursos universitários, especialmente, no curso de medicina. Igualmente, torna-se presente na chamada Comissão Nacional da Verdade (ou Comissão da Verdade), "colegiado instituído pelo governo do Brasil para investigar as graves violações de direitos humanos ocorridas entre 18 de setembro de 1946 e 5 de outubro de $1988^{\prime \prime 27}$.

O problema da verdade, no plano legislativo, só pode ser apresentado na forma fragmentada e de maneira diversa. Mas a obrigação de buscar a verdade também existe para as jurisdições abaixo da Lei Fundamental, tornando-se uma premissa fundamental à realização da equidade e da justiça. Vê-se a verdade como uma premissa fundamental de todo o sistema jurídico e jurisdicional. Ela está presente no direito processual direito penal (fundado na verdade material) e no direito civil e consumerista (fundado na confiança e na responsabilidade objetiva), também, no direito tributário, no direito trabalhista, administrativo etc.

Todavia, do ponto de vista político, a democracia pluralista depara-se com três áreas problemáticas da questão da verdade: nos conflitos sobre a relação entre verdade e maioria, no entendimento da formação da opinião pública da sociedade e, como parte disso, na limitação da liberdade de imprensa a favor do interesse de outros valores protegidos e as suas orientações referentes à crônica jornalística "fidedigna à verdade" (ao invés da mentira mediática ou fake new $)^{28}$.

Resumidamente, o fundamento da verdade como direito radica na ideia de que esta (a verdade) é o direito que possibilita a concretização dos demais direitos e, em especial, os direitos humanos e fundamentais e, especificamente, os princípios que servem de fundamento à cidadania e à dignidade prescritos na $\mathrm{CF}$.

\subsection{Verdades práticas para uma razão comum}

Numa época em que todos se questionam sobre as bases e fundamentos possíveis da normatividade jurídico-moral, o multiculturalismo aponta para uma racionalidade que não depende diretamente do sujeito, mas da intersubjetividade, uma lógica de descentralização em relação ao ego.

Mas, para melhor entender o multiculturalismo é importante partirmos de uma definição dos conceitos "cultura" e "culturalismo". Assim, o vocábulo cultura pode ser significado como um conjunto de características humanas que se criam, se preservam e se aprimoram, por meio da comunicação, da educação e da cooperação entre indivíduos em sociedade. É, pois, um aspecto importante da vida coletiva, relacionado à produção e à transmissão de conhecimentos e valores que orientam a convivência e distinguem as sociedades. Já, a palavra culturalismo é o construto segundo o qual se considera que a cultura de cada sociedade consiste numa realidade objetiva, de natureza coletiva e que escapa ao controle dos indivíduos, sendo dotada de coerência e especificidade próprias.

27 Informação disponível em: https://www.politize.com.br/comissao-nacional-daverdade/?https://www.politize.com.br/\&gclid=CjwKCAjwm_P5BRAhEiwAwRzSO_s331jL0BTz-

WyE2F6NIxO58s-hx37fW2FKcsX_ZdIbhqRGuMcPuxoCLIEQAvD_BwE. Acesso em: 18 de agosto de 2020.

${ }^{28}$ HÄBERLE, Peter. Os problemas da verdade no estado constitucional. Trad. Urbano Carvelli. Porto Alegre: Sergio Antonio Fabris Ed., 2008. p. 113.

Revista de Direito Brasileira | Florianópolis, SC | v. 27 | n. 10 | p.14-30 | Set./Dez. 2020 
Multiculturalismo, assim, seria um conceito concreto, por meio do qual designamos uma realidade (objetiva) que é constituída de características humanas diversas, próprias das sociedades modernas, mas que pode ser estudada num contexto global. É nesse sentido que pode ser considerado o multiculturalismo uma problemática do mundo moderno.

Com efeito, há diferenças no estado de desenvolvimento sociocultural dos países, isso deve ser o motivo pelo qual existem diversas maneiras de compreender, abordar e resolver um determinado grupo de problemas (dilemas). Mas, é preciso lembrar que essa diversidade cultural passou a ser considerada patrimônio comum da humanidade e, a sua tutela, um imperativo ético inseparável em face da dignidade da pessoa humana. A proteção dos conteúdos culturais pelas políticas e medidas nacionais ou regionais, dirigidas a este fim, não exclui o reconhecimento da interculturalidade enquanto interação equitativa de diversas culturas que possam gerar, por meio do diálogo e do respeito mútuo, novas expressões culturais compartilhadas. Os conteúdos éticos presentes nos termos equidade, diálogo e respeito são suficientes para responder uma vez mais a toda pretensão ou teoria que não leve em conta as identidades culturais (v. Pluralismo $\left.{ }^{29}\right)^{30}$.

O protótipo da democracia pluralista se apresenta hoje como o mais bem sucedido modelo antagônico ao Estado totalitário e a todas as pretensões fundamentalistas de verdade, ao monopólio de informação e às ideologias imutáveis. Assim, ele se caracteriza exatamente pelo fato de não estar em posse das verdades eternas pré-constituídas, mas sim de ser predestinado apenas a uma mera busca da verdade. Ele se funda sobre verdades provisórias, revidáveis, as quais ele, a princípio, acolhe no plural e não no singular e, também, não as decreta. Logo, tendo em vista o problema da verdade no Estado Democrático de Direito, a ciência jurídica há de ser compreendida como uma "ciência cultural". Talvez, por esse motivo, a verdade forçada com a maioria não seja certamente a verdade final, razão pela qual as condições culturais da verdade também sejam consideradas. E, frequentemente, as comissões de inquérito estão e permanecem atoladas sobre um caminho muito logo na busca da verdade ${ }^{31}$.

Essa complexidade sociocultural manifesta-se, fundamentalmente, nas inúmeras concepções, modelos e práticas (decisões) que têm como objeto as experiências históricas e modernas. De qualquer forma, do ponto de vista jurídico-ético, desenvolveu-se, nas últimas décadas, uma corrente de direito alternativo que, apoiando-se na filosofia e na ética dos direitos humanos, busca, por meio dos ordenamentos jurídicos, da cultura jurídica e das práticas dos seus operadores, diferentes formas emancipadoras e de transformação social. Destacam-se, por um lado, a proposta de Arturo Andrés Roig de uma moral da emergência, que acentua a subjetividade como momento de irrupção do outro, o diverso, diante das formas opressivas e unificadoras da eticidade vigente; e por outro lado, a ética da libertação de Enrique Dussel, que parte de uma racionalidade

\footnotetext{
${ }^{29}$ [Por estas y otras razones la Bioética latinoamericana necesita reflexionar sobre la diversidad lingüística y cultural de las sociedades a las que se dirige (v. Diversidad lingüística y sistemas de significación), y debe recomendar el respeto de esta diversidad tal como ha quedado estipulado en la Convención de la Unesco. La diversidad cultural ha pasado a ser un patrimonio común de la humanidad y su defensa, un imperativo ético inseparable del respeto a la dignidad de la persona humana. La protección de los contenidos culturales por políticas y medidas nacionales o regionales dirigidas a este fin no excluye el reconocimiento de la interculturalidad en tanto interacción equitativa de diversas culturas que puedan generar a través del diálogo y el respeto mutuo nuevas expresiones culturales compartidas (v. Diversidad cultural y biopolíticas). Los contenidos éticos presentes en los términos equidad, diálogo y respeto son suficientes para responder una vez más a toda pretensión de una teoría y práctica de la Bioética que no tenga en cuenta las identidades culturales (v. Pluralismo)"].

${ }^{30}$ TEALDI, Juan Carlos. Diccionario latinoamericano de Bioética. Bogotá: UNESCO - Red Latinoamericana y del Caribe de Bioética: Universidad Nacional de Colombia, 2008, p. 35.

${ }^{31}$ HÄBERLE, Peter. Os problemas da verdade no estado constitucional. Trad. Urbano Carvelli. Porto Alegre: Sergio Antonio Fabris Ed., 2008. p. 36, 44, 105, 106.
} 
material (re)produtiva, sustentada na vida humana como critério da verdade, e oferece ferramentas para o exercício de uma racionalidade prática $^{32}$.

O multiculturalismo é uma problemática que exige uma investigação "científico-crítica" acerca das razões das diversas formas de resolver os dilemas nascidos da oposição entre valores e princípios, visando a identificar aqueles recursos considerados primários (e comuns) da sociedade mundial.

Existe, contudo, a possibilidade de se pensar a sociedade mundial como uma "realidade" definida pelos próprios valores comuns e universais: vida, convivência, paz, respeito, colaboração, dignidade etc. Com efeito, o reconhecimento da existência de uma unidade (identidade) mundial nos permite, também, afirmar que existem condições homogêneas que propiciam a idealização de um modelo jurídico que permita disseminar esses recursos hermenêutico-argumentativos.

Certamente, e como consequência do pluralismo cultural, ensina Habermas ${ }^{33}$ :

O mundo se revela e é interpretado de modo diferente segundo as perspectivas dos diversos indivíduos e grupos - pelo menos num primeiro momento. Uma espécie de pluralismo interpretativo afeta a visão de mundo e a autocompreensão, bem como a percepção dos valores e dos interesses de pessoas cuja história individual tem suas raízes em determinadas tradições e formas de vida e é por elas moldadas. É essa multiplicidade de perspectivas interpretativas que explica por que o sentido do princípio de universalização não se esgota numa reflexão monológica segundo a qual determinadas máximas seriam aceitáveis como leis universais. É só na qualidade de participantes de um diálogo abrangente e voltado para o consenso que somos chamados a exercer a virtude cognitiva da empatia em relação às nossas diferenças recíprocas na percepção de uma mesma situação. Devemos então procurar saber como cada um dos demais participantes procuraria, a partir do seu próprio ponto de vista, proceder à universalização de todos os interesses envolvidos.

Mas, diferentemente de outros autores, acreditamos na possibilidade real de idealizar um tipo de instrução moral que tenha como objetivo difundir as verdades práticas. Elas devem ser descobertas por meio de procedimentos argumentativos que, como critérios de correção das verdades, sejam capazes de permitir o confronto do nosso ponto de vista com o ponto de vista dos outros $^{34}$.

Devido aos motivos anteriormente apontados, defendemos a teoria da coerência, isto é, da "verdade como a inserção infrangível de uma sentença no contexto geral das declarações científicas, assim como a "teoria do consenso" de Jürgen Habermas. Ele compreende verdade como a conformidade de uma alegação ou, respectivamente, com a capacidade de consenso no discurso dos participantes, o qual, entretanto, está sob a ideia orientadora de um "diálogo livre" e "universal". Esta tentativa só poderá ser concretizada quando os estado e a sociedades modernas investirem na educação de seus (jovens) cidadãos, disseminando, assim, a ideal do respeito à pessoa humana, condição que é compatível com o postulado da busca da verdade no contexto de seus valores básicos: objetivos como, entre outros, amor pela verdade, veracidade, tolerância, democracia e reconciliação dos povos estão moldados em algumas constituições dos Estados da Amárica Latina e, desenvolvidos, consequentemente, segundo modelo da Declaração dos Direitos Humanos das Nações Unidas de 1948. Em suma, a educação da espécie humana começa com o

\footnotetext{
32 ARPINI, Adriana. Pluralismo. In: TEALDI, Juan Carlos. Diccionario latinoamericano de Bioética. Bogotá: UNESCO - Red Latinoamericana y del Caribe de Bioética: Universidad Nacional de Colombia, 2008 , p. 36.

${ }^{33}$ HABERMAS, Jürgen. A ética da discussão e a questão da verdade. Organização e introdução de Patrick Savidan; trad. Marcelo Brandão Cipolla. São Paulo: Martins Fontes, 2004, p. 10.

${ }^{34}$ HABERMAS, Jürgen. A ética da discussão e a questão da verdade. Organização e introdução de Patrick Savidan; trad. Marcelo Brandão Cipolla. São Paulo: Martins Fontes, 2004, p. 10.

Revista de Direito Brasileira | Florianópolis, SC | v. 27 | n. 10 | p.14-30 | Set./Dez. 2020
} 
ensinamento dos direitos humanos, da tolerância e da democracia (o que também abarca o ensinamento da repudia à violência) e culmina no ensino do respeito ao meio ambiente ${ }^{35}$.

\section{CONCLUSÃO}

Como resultado do presente ensaio considera-se a verdade um direito humano e fundamental necessário à concretização dos demais direitos, da cidadania, da justiça e do bem comum. Nesta perspectiva, a verdade seria como a luz que irradia a justiça no contexto do Estado Democrático de Direito, onde a liberdade (religiosa, política, de opinião etc.) é a sua condição sine qua non, isto é, necessária e indispensável para a resolução dos problemas vinculados ao bem comum.

A verdade como direito humano e fundamental se constitui em alicerce da democracia e do multiculturalismo. Diz-se, assim, de um conceito que se aprimora, por meio da comunicação, da educação e da cooperação entre indivíduos em sociedade.

$\mathrm{O}$ direito à verdade é importante para a vida coletiva e está dialeticamente relacionado à produção e à transmissão de conhecimentos e valores que orientam a convivência e distinguem as sociedades.

Neste sentido, os valores fundamentais funcionam como verdades jurídicas que colocam limites à violação de direitos e, também, à tolerância na convivência social, por exemplo, contra as tentativas de introduzir a ideia de uma sociedade livre, sem justiça ou justa, mas sem liberdade.

A verdade como direito a ser concretizado somente será possível por meio de uma educação formadora da personalidade moral que aponte para uma moralidade pública constitutiva da base sociocultural dos Estados Democráticos de Direito.

É, por meio dessa educação instrumental (funcional) que os jovens devem ser educados em face da edificação de uma consciência da responsabilidade ética e política. A busca pela justiça, a equidade o do bem comum começa pela verdade, sendo essa uma das principais premissas na construção de um Estado Democrático de Direito.

\section{REFERENCIAS}

ALEXY, Robert. Teoria da argumentação jurídica: a teoria do discurso racional como teoria da fundamentação jurídica. Trad. Zilda Hutchinson Schild Silva; rev. e introdução à edição brasileira Claudia Toledo. 2 ed. São Paulo: Landy, 2005.

ARPINI, Adriana. Pluralismo. In: TEALDI, Juan Carlos. Diccionario latinoamericano de Bioética. Bogotá: UNESCO - Red Latinoamericana y del Caribe de Bioética: Universidad Nacional de Colombia, 2008.

BRASIL. Constituição (1988). Constituição da República Federativa do Brasil de 1988. Disponível em: http://www.planalto.gov.br/ccivil_03/Constituicao/Constituiçao.htm. Acesso em: 29 abr. 2020.

BRASIL. Lei $n$. 8.078, de 11 de setembro de 1990. Disponível em: http://www.planalto.gov.br/ccivil_03/leis/18078compilado.htm. Acesso em: 29 abr. 2020.

BUNGE, Mario. Tratado de Filosofia Básica. Semântica II: Sentido e Referência. Trad. de Leônidas Hegenberg e Octanny S. da Mota. São Paulo: E.P.U Ed. da Universidade de São Paulo, $1976 b$.

${ }^{35}$ HÄBERLE, Peter. Os problemas da verdade no estado constitucional. Trad. Urbano Carvelli. Porto Alegre: Sergio Antonio Fabris Ed., 2008. p. 33, 106-107. 
DESCARTES, René. Discurso do método. Trad. Lourdes Nascimento Franco. São Paulo: Ícone, 2006.

GRAYLING, A. C. Epistemologia, in BUNNIN, Nicholas e E.P. Tsui-James (orgs). "Compendio de Filosofia". São Paulo: Loyola, 2002.

HÄBERLE, Peter. Os problemas da verdade no estado constitucional. Trad. Urbano Carvelli. Porto Alegre: Sergio Antonio Fabris Ed., 2008.

HABERMAS, Jürgen. A ética da discussão e a questão da verdade. Organização e introdução de Patrick Savidan; trad. Marcelo Brandão Cipolla. São Paulo: Martins Fontes, 2004.

MacCORMICK, Neil. Argumentação jurídica e teoria do direito. Trad. Waldéa Barcellos revisão da tradução Marylene Pinto Michael. São Paulo: Martins fontes, 2006.

POPPER, Karl. R. Conhecimento objetivo: uma abordagem evolucionária. Trad. de Milton Amado. Belo Horizonte: Itatiaia, 1999, p. 15.

ROBLES, Gregorio. $O$ direito como texto: quatro estudos de teoria comunicacional do direito. Trad. de Roberto Barbosa Alves. Barueri, SP: Manole, 2005.

TEALDI, Juan Carlos. Diccionario latinoamericano de Bioética. Bogotá: UNESCO - Red Latinoamericana y del Caribe de Bioética: Universidad Nacional de Colombia, 2008. 